\title{
Thyroxine: A Putative Neuroprotectant in Diabetes Induced Peripheral Neuropathy in Rats
}

\author{
Hariprasad MG ${ }^{1 *}$, Rema Razdan ${ }^{1}$, Yasha TC ${ }^{2}$ and Tripathy Amrutanand $\mathbf{S}^{3}$ \\ ${ }^{1}$ Department of Pharmacology, Al-Ameen College of Pharmacy, Bangalore-560027, Karnataka, India \\ ${ }^{2}$ Department of Neuropathology, NIMHANS, Bangalore, Karnataka, India
}

${ }^{3}$ Department of Pharmacognosy, Al-Ameen College of Pharmacy, Bangalore-560027, Karnataka, India

\begin{abstract}
Objectives: The treatment options for diabetic peripheral neuropathy (DPN) currently include anti-depressants, anti-convulsants and opioid analgesics. These agents are modestly effective for symptomatic relief, but they do not affect the underlying pathology nor do they slow progression of the disease. Therefore, effective treatment for diabetes induced neuropathy would be a major advantage for patients. It is well established. TH plays an important role in regulating the development and regeneration of the nervous system and local administration of triiodothyronine (T3) at the level of transected rat sciatic nerve increased the number and diameter of regenerated axons and SCG10 protein levels about two-fold in the different segments of transected nerve during the regeneration period. Thyroxine (T4) has shown the range of biological actions and is important in both development and maturation. The etiology of diabetic neuropathy revolves around, AGE formation, lipid peroxidation, oxidative stress etc. All these have been reported to stimulate inflammatory processes, which lead to DPN. Progression in DPN can cause functional and behavioral deficits. Therefore, the present study was undertaken to evaluate the protective effect of thyroxine in diabetes induced peripheral neuropathy in rats.
\end{abstract}

Methods: Experimental diabetes in rats was induced by single intraperitoneal (i.p.) injection of Streptozotocin (SIGMA-ALDRICH, USA) at a dose of $55 \mathrm{mg} / \mathrm{kg}$ i.p. freshly dissolved in $100 \mathrm{mM}$ sodium citrate buffer, $\mathrm{pH} 4.5$. The degree of protection was determined by measuring behavioural parameters like motor in-coordination, thermal andcold hyperalgesia, grip strength, electrophysiological properties of sciatic nerve like nerve conduction velocity, and histopathological studies.

Results: DPN was evidenced in diabetic control rats and ameliorated with administration of Thyroxine (T4) $(1 \mathrm{mg} / \mathrm{kg}$, s.c.) thrice a week for 5 weeks by augmenting all the above parameters.

Conclusions: T4 exhibited neuroprotective activity, which would be attributed to its activity as neurotrophic effect.

Keywords: Nerve; Anti-oxidants; Diabetes; Neuropathy; STZ; Thyroxine

\section{Introduction}

Diabetes mellitus (DM) is a worldwide major health problem. It is a chronic metabolic disorder characterized by hyperglycemia resulting from inadequate secretion or impaired action of endogenous insulin. The prevalence of diabetes is increasing worldwide and is believed to increase to 300 million by the year 2030 [1].

Poorly controlled or persistent hyperglycemia in DM leading to several micro vascular and macro vascular complications. DPN is a common micro vascular complication affecting more than $50 \%$ of the diabetic patients [2].

The pathogenesis of diabetic peripheral neuropathy (DPN) is complex and resulting from contributions of various pathways including metabolic and vascular factors, which consists of activation of polyol pathway, advanced glycation end products pathway, hexosamine pathway, increased activity of mitogen-activated protein kinase (MAPK), protein kinase C, poly (ADP-ribose) polymerase, oxidative stress, apoptosis, impaired neurotrophic support, autoimmunity, inflammation, and up regulation of endothelins [3].

The impairment of nerve function is a well-established early manifestation of diabetes both clinically and in experimental animal models. DPN causes dysfunction of small and large nerve fibers and negatively impacts quality of life in diabetic patients. Small-fiber peripheral neuropathy is characterized by behavioral abnormalities (cold, thermal hyperalgesia, loss of grip strength, motor coordination, burning or lancinating pain, paresthesia, and hyperesthesia and predisposition to foot ulceration). Large-fiber dysfunctions include loss of position and vibration sensation, nerve-conduction abnormalities, and distal muscle weakness. Early disorders of nerve function include slowing in nerve conduction velocity (NCV), followed by axonal degeneration, axoglial disjunction, loss of fiber density and microangiopathy [4].

A number of different agents from diverse chemical classes have entered clinical trials for the treatment of metabolic abnormalities in DPN, but only few approved for clinical use while other drugs either ineffective or withdrawn [2].

Current treatment options for symptomatic treatment of DPN include antidepressants, anticonvulsants. These agents are modestly

*Corresponding author: Hariprasad MG, Department of Pharmacology, Al-Ameen College of Pharmacy, Hosur Road, Near Lalbagh Main Gate, Bangalore-560027, Karnataka, India, Tel: 080-22234619, +91-9845117850; Fax: 08022225834; E-mail: hariprasadmg2004@yahoo.com

Received July 30, 2015; Accepted August 22, 2015; Published August 26, 2015

Citation: Hariprasad MG, Razdan R, Yasha TC, Amrutanand ST (2015) Thyroxine: A Putative Neuroprotectant in Diabetes Induced Peripheral Neuropathy in Rats. $J$ Diabetes Metab 6: 595. doi:10.4172/2155-6156.1000595

Copyright: ( 2015 Hariprasad MG, et al. This is an open-access article distributed under the terms of the Creative Commons Attribution License, which permits unrestricted use, distribution, and reproduction in any medium, provided the original author and source are credited. 
effective for symptomatic relief, but they affect the underlying pathology nor do they slow progression of the disease [5]. Hence, a novel approach to bridge the gap in selecting the compound in treatment of DPN was used. The discovery of use of a drug for a new indication is an arbitrary process, as known by many past examples like the use of zinc acetate for the treatment of Wilson's disease, arsenic for acute promyelocytic leukemia [6], amphotericin B for leishmaniasis and thalidomide for multiple myeloma [7]. The discovery of these "alternative" uses for drugs different from originally intended drug development process is referred to as drug repurposing or repositioning [8].

The main advantage of repositioning of drug efforts is that pharmacokinetics and pharmacodynamics of the drug are known, repositioning discoveries are less costly and quicker than traditional discovery efforts, which usually take 10-15 years [9] and cost upward of $\$ 1$ billion [10]. Although physicians and pharmaceutical/ biotechnology companies have manual methods and prior knowledge that enable them to carry out drug repositioning clinical trials, such successful repositioning of drugs is often serendipitous and rare. In this study we have selected thyroxine to explore for its activity in DPN

Thyroid hormones (TH) [T4 (tetraiodothyronine) and T3 (triiodothyronine)], the only iodine -containing compounds with biological activity [11], TH stimulate synthesis of $\mathrm{Na}^{+} \mathrm{K}^{+}$ATPase and also regulates metabolism by stimulating protein synthesis and increase the use of glucose and fatty acids for ATP production. They also increase lipolysis and enhance cholesterol excretion [12]. The cardiac side effect of D isomer of thyroxine resulted discontinuation of the clinical uses of these hormone. Under normal conditions, about $41 \%$ of thyroxine is converted to T3, and about $21 \%$ is converted to metabolically inactive 3, 3, 5-triiodothyronine (reverseT3, rT3). $\mathrm{T} 3$ is a powerful inducer of pancreatic acinar cell proliferation in rodents [13]. In-vitro studies of human and rodent insulinoma cell lines showed that T3 protected from apoptosis and induces $\beta$-cell growth and proliferation [14]. A serendipitous, positive association between serum-FT3 (free tri iodothyronine) and an estimate of insulin production was found in euthyroid, lean, healthy individuals [15]. Treatment of Human pancreatic duct cells (hPANC-1) with T3 induced changes in cell morphology, promotes cell differentiation into insulin-producing $\beta$-cells, upregulated insulin and glucose transporter protein-2 transcripts, and increases insulin release into the medium [16]. TH receptor has been identified in pancreatic $\beta$-cell lines [14], T3-enhanced insulin release in isolated rat pancreatic islets exposed to glucose concentrations of $2-8 \mathrm{mmol} / \mathrm{l}$, had no effect at concentrations of $12 \mathrm{mmol} / \mathrm{l}$, and inhibited insulin release at concentrations of 16.6 $\mathrm{mmol} / \mathrm{l}[17] \mathrm{T} 3$ promoted expression of important proteins involved in both glucose and lipid metabolism that may influence insulin secretion [18]. Therefore, the present study was designed to evaluate whether diabetes induced DPN can be reversed by treatment with thyroxine.

\section{Materials and Methods}

\section{Experimental animals}

Adult Male Wistar rats $(n=6)$ weighing between 200-250 g were included for the study. All rats were maintained under standard housing condition at controlled temperature at $25^{\circ} \mathrm{C} \pm 2^{\circ} \mathrm{C}$ with $12 \mathrm{hr}$ light/dark cycle with food and water provided standard rat diet and water ad labium. Animals which do not comply with above criteria, and which are found to be diseased will be excluded from the study. After one-week adaptation period, the healthy animals were used for the study. All the protocols were approved by Institutional Animal Ethical Committee. IAEC NO: AACP/P-48, India.

\section{Induction of diabetes}

Experimental diabetes in rats was induced by single intraperitoneal (i.p.) injection of Streptozotocin (STZ) (SIGMA-ALDRICH, USA) at a dose of $55 \mathrm{mg} / \mathrm{kg}$ i.p. freshly dissolved in $100 \mathrm{mM}$ sodium citrate buffer, $\mathrm{pH} 4.5$ [19]. Equal volume of vehicle was injected to non-diabetic rats. After 48 hours, blood samples were collected from rat's tail vein, serum was isolated. Blood serum glucose levels were estimated to confirm the development of diabetes using glucose oxidase peroxides (GOD-POD) diagnostic kit method. Animals with fasting blood glucose levels $\geq 250$ $\mathrm{mg} / \mathrm{dl}$ were selected for the study. Following the induction of diabetes, rats were then kept for the next $24 \mathrm{~h}$ on $5 \%$ glucose solution bottles in their cages to prevent hypoglycemia due to immediate oxidative degeneration of beta cells.

\section{Experimental design}

Eighteen rats were randomly divided into three groups (Group I-Group III). Group I served as normal control group. Group II and Group III were induced diabetes and included in the study as experimental rats. Group II served as diabetic control group whereas Group III received T4 (1 mg/kg, s.c.) [20] thrice a week for 5 weeks. Treatment was started from day 2 of STZ administration. Rats were administered insulin (3IU/day, s.c.) [21] for the complete period of the study. After 5 weeks various behavioral biochemical, electrophysiological parameters were determined to evaluate the severity of diabetic neuropathy in treated group as compare to normal and diabetic control group. The researchers carrying out the behavioral studies were blinded with respect to the treatment administered.

\section{Drugs, chemicals and instruments}

Thyroxine procured as a research gift sample from Apotex Pharmachem India Pvt. Ltd. Thiopentone Sodium, Anaesthetic Ether, Micro-pipette and Micro-centrifuge tubes, Bioamplifier, PowerLab were procured from respective companies Neon Laboratories, Sd FineChem Ltd, Tarsons Productions Pvt. Ltd., AD Instrument, Australia

\section{Assessment of general toxicity}

To assess the general condition of animals, they were examined daily for clinical signs such as alopecia, piloerection or hind limb weakness and mortality. Body weight was measured using digital balance (Essae DS-252). Loss of body weight was compared between body weight measured at the beginning and at the end of the study.

\section{Behavioral parameters}

\section{Assessment of thermal and cold hyperalgesia [22]}

Tail immersion test (warm water): Rat's tail was marked at lower $5 \mathrm{~cm}$ portion and immersed in warm water bath $\left(46^{\circ} \mathrm{C}\right)$. The withdrawal response of tail or sign of struggle was observed and the reaction time was recorded using stop watch (cut-off time $12 \mathrm{sec}$ ). The tail was dried carefully after recording every response. The reaction time was recorded before and after treatment in normal, diabetic and treated groups. Reductions in tail withdrawn time specify hyperalgesia.

Tail immersion test (cold water): The lower half portion of the tail was immersed in a beaker of cold water $\left(4^{\circ} \mathrm{C}\right)$. Tail withdrawal or flicking response from cold water was recorded as the reaction time (cutoff time10 Sec) in seconds. Shortenings in tail withdrawn time stipulate cold hyperalgesia.

Rota-Rod performance test [23]: Motor coordination was evaluated by a Rota-Rod apparatus. The Rota-Rod unit consists of a 
rotating rod, $75 \mathrm{~mm}$ in diameter, which was divided into four parts by compartmentalization to permit the testing of four rats at a time. Briefly, in a training session, the rats were placed on the rod that was set to 15 RPM and the performance time that each rat was able to remain on the rota-rod was recorded. The rats were subjected to three training trials from $3 \mathrm{~h}-4 \mathrm{~h}$ intervals on two separate days for acclimatization purposes. In the test session, the rats were placed on the rota-rod and their performance times were recorded. All the readings were taken in triplicate.

Grip Strength measurement [24]: The grip strength meter was used for evaluating grip strength of the animals. Before commencement of the experiment the animals were acclimatized by placing them on the instrument for a few minutes. Rats were held by the tail above the grid of grip strength meter to an almost horizontal position. The base of the tail was then pulled following the axle of the sensor until it released the grid. The force achieved by the animal was then displayed on the screen and was recorded as Newton.

\section{Biochemical parameters}

Glycosylated hemoglobin (GHb) [25]: At the end of study 5 weeks blood was withdrawn from tail vein of rat and collected in EDTA tubes. The GHb was determined by using commercially available kit.

A hemolysed preparation of whole blood is mixed continuously for 5 minutes with a weakly binding cation-exchange resin. The labile fraction is eliminated during the hemolysate preparation. During the mixing, $\mathrm{HbAo}$ binds to the ion exchange resin leaving $\mathrm{GHb}$ free in the supernatant. After the mixing period, a filter separator is used to remove the resin from the supernatant. The percent $\mathrm{GHb}$ is determined by measuring absorbance of the $\mathrm{GHb}$ fraction and the total hemoglobin $(\mathrm{THb})$ fraction. The ratio of the absorbance of the $\mathrm{GHb}$ and the $\mathrm{THb}$ fraction of the Control and the Test is used to calculate the percentage $\mathrm{GHb}$ of the sample using below formula.

$$
\text { Ratio of Control }(\text { Rc })=\frac{\text { Abs. Control GHb }}{\text { Abs.Control THb }}
$$

$$
\begin{aligned}
& \text { Ratio of test }(\text { Rt })=\frac{\text { Abs. Test GHb }}{\text { Abs. Test THb }} \\
& \text { GHb in } \%=\frac{\text { Ratio of test }}{\text { Ratio of Control }} \times 10
\end{aligned}
$$

\section{Isolation of sciatic nerve}

The rats were anesthetized by intra peritoneal administration of thiopentone sodium, $30 \mathrm{mg} / \mathrm{kg}$ [20]. After anesthesia, rat backs were shaved and NCV was recorded. Briefly incision is made at $\mathrm{L}_{4}-\mathrm{L}_{6}$ spinal segments. The sciatic nerves were surgically exposed from sciatic notch to the gastrocnemius tendon and the left and right sciatic nerves were rapidly removed carefully impregnated on fine filter paper to remove any accompanying blood, soaked for 10 minutes in Ringer-Locke buffer to prevent spontaneous firing of the nerve [26].

Preparation of nerve homogenate: A segment of sciatic nerve, approximately $1.5 \mathrm{~cm}$ in length, $5 \mathrm{~mm}$ proximal and $5 \mathrm{~mm}$ distal was used for preparing the $10 \% \mathrm{w} / \mathrm{v}$ homogenates for biochemical estimation. Tissue homogenates were prepared in $0.1 \mathrm{M}$ phosphate buffer ( $\mathrm{pH}$ 7.4). The homogenate was centrifuged at $1000 \mathrm{rpm} 4^{\circ} \mathrm{C}$ for $3 \mathrm{~min}$ and the supernatant divided into two portions, one of which was used for measurement of lipid peroxidation (LPO) and the remaining supernatant was again centrifuged at $12,000 \mathrm{rpm}$ at $4^{\circ} \mathrm{C}$ for $15 \mathrm{~min}$ and used for the measurement of endogenous antioxidants such as superoxide dismutase (SOD), catalase (CAT) glutathione (GSH) [27].

Measurement of lipid peroxidation: The extent of lipid peroxidation in terms of thiobarbituric acid reactive substances (TBARS) formation was measured according to the method of Esterbauer and Cheeseman. Tissue extracts were mixed separately with $1 \mathrm{ml}$ TCA (20\%), $2 \mathrm{ml} \mathrm{TBA}(0.67 \%)$ and heated for $1 \mathrm{~h}$ at $100^{\circ} \mathrm{C}$. After cooling, the precipitate was removed by centrifugation. The absorbance of each sample was measured at $535 \mathrm{~nm}$ using a blank containing all the reagents except the sample. As 99\% TBARS are malondialdehyde (MDA), so TBARS concentrations of the samples were calculated using the extinction coefficient of MDA, which is $1.56 \times 10^{5} \mathrm{M}^{-1} \mathrm{~cm}^{-1}$ and were expressed as $\mu \mathrm{M}$ of malondialdehyde per mg protein [28].

Measurement of superoxide dismutase (SOD) and catalase activity: Sciatic nerve homogenate was centrifuged at $4^{\circ} \mathrm{C}, 17,500 \times \mathrm{g}$ for $10 \mathrm{~min}$. Supernatant was used for the measurement of SOD activity by pyrogallol autooxidation method [29] and catalase activity by $\mathrm{H} 2 \mathrm{O} 2$ degradation method, which is a quantitative spectroscopic method developed for following the breakdown of $\mathrm{H}_{2} \mathrm{O}_{2}$ at $240 \mathrm{~nm}$ in unit time. The sample readings were taken by placing $1 \mathrm{ml}$ of phosphate buffer and $100 \mu \mathrm{l}$ of tissue homogenate in the reference cuvette and $1 \mathrm{ml}$ of $\mathrm{H}_{2} \mathrm{O}$ and $100 \mu \mathrm{l}$ of homogenate in the test cuvette in the spectrophotometer. For each measurement, the reading was taken at $240 \mathrm{~nm} 1 \mathrm{~min}$ after placing the cuvettes in Shimadzu spectrophotometer [30].

Measurement of reduced glutathione (GSH) activity: Reduced glutathione was assayed by the method of Van Dooran [31]. Briefly $1.0 \mathrm{ml}$ of sciatic nerve homogenate $(10 \% \mathrm{w} / \mathrm{v})$ was precipitated with $1.0 \mathrm{ml}$ of sulphosalicylic acid (4\%). The samples were kept at $4^{\circ} \mathrm{C}$ for at least $1 \mathrm{~h}$ and then subjected to centrifugation at $1200 \mathrm{~g}$ for $15 \mathrm{~min}$ at $4^{\circ} \mathrm{C}$. The assay mixture contained $0.1 \mathrm{ml}$ supernatant, $2.7 \mathrm{ml}$ phosphate buffer (0.1 M, pH 7.4) and $0.2 \mathrm{ml} \mathrm{5,5,} \mathrm{dithiobis} \mathrm{(2-nitro} \mathrm{benzoic} \mathrm{acid)}$ (Ellman's reagent, $0.1 \mathrm{mM}, \mathrm{pH} 8.0$ ) in a total volume of $3.0 \mathrm{ml}$. The yellow colour developed was read immediately at $412 \mathrm{~nm}$ and the reduced GSH levels were expressed as $\mu \mathrm{g} / \mathrm{mg}$ protein.

\section{Electrophysiological parameters}

Measurement of Nerve Conduction Velocity (NCV): The left sciatic nerves were then placed in a moist nerve chamber (MLT016/B AD Instruments, Australia) to measure NCV. NCV was measured by stimulating proximally at the sciatic notch by stimulating electrode (MLA270 AD Instruments, Australia) with $10 \mathrm{mV}$ at $1 \mathrm{~Hz}$ to $5 \mathrm{~Hz}$ and the action potential was measured using recording electrodes (MLA 285) by placing distally to the sciatic notch. NCV was calculated by using the following formula:

$$
\text { Nerve Conduction velocity }\left(\frac{\mathbf{m}}{\text { sec }}\right)=\frac{\text { distance }}{\text { latency }}
$$

\section{In-vitro glycation of proteins [32]}

To determine in vitro glycation of protein bovine serum albumin (BSA)-glucose assay was performed based on the procedure of Brownlee et al. BSA $(10 \mathrm{mg} / \mathrm{mL})$ was incubated with glucose $(500 \mathrm{mM})$ in phosphate buffered-saline ( $\mathrm{pH} 7.4$ ) and extract containing sodium azide $(0.02 \%)$ at $37^{\circ} \mathrm{C}$ with a final concentrations of BSA $(2 \mathrm{mg} / \mathrm{mL})$, glucose $(40 \mathrm{mM})$, sample $(0.1$ to $0.5 \mathrm{mg} / \mathrm{mL})$. Sterilization of reagents and samples were done by filtration through $0.2 \mu \mathrm{m}$ membrane filters. Amino guanidine was used as an inhibitor positive control and reactions without any inhibitor were also setup. All the samples and positive control were kept for incubation at $37^{\circ} \mathrm{C}$ for 15 days. After 15 days of incubation, fluorescence intensity (excitation wavelength of 
Citation: Hariprasad MG, Razdan R, Yasha TC, Amrutanand ST (2015) Thyroxine: A Putative Neuroprotectant in Diabetes Induced Peripheral Neuropathy in Rats. J Diabetes Metab 6: 595. doi:10.4172/2155-6156.1000595

Page 4 of 9

$370 \mathrm{~nm}$ and emission wavelength of $440 \mathrm{~nm}$ was measured for the test solutions. Percent inhibition was calculated as follows:

Inhibition $\%=(1-(\mathrm{As}-\mathrm{Ab})(\mathrm{Ac}-\mathrm{Ab}) \times 100$

Where As = fluorescence of the incubated mixture with sample, Ac, $\mathrm{Ab}=$ are the fluorescence of the incubated mixture without sample as a positive control and the fluorescence of incubated mixture without sample as a blank control.

\section{Histopathological studies}

The right sciatic nerves were isolated and transferred in to 0.05 $\mathrm{mol} / \mathrm{L}$ phosphate buffered (30 g/L) glutaraldehyde solution for histopathological studies (H\&E, Kulchitsky Pal staining and Massion's trichome staining).

\section{Statistical analysis}

Statistical evaluations were done by ANOVA, expressed as mean \pm S.E.M. followed by Bonferroni comparison test using Graph Pad In Stat (Ver.3.10) and Graph Pad Prism 5 computer program. $\mathrm{P}<0.05$ was considered statistically significant.

\section{Results}

\section{Assessment of general toxicity}

The percentage body weight of normal and diabetic rats at $5^{\text {th }}$ week was found to be $26.87 \pm 1.74 \mathrm{~g},-15.90 \pm 0.769 \mathrm{~g}$. The percentage of change of body weight of diabetic rats significantly less $(\mathrm{P}<0.001)$ as compared to normal control, similarly the percentage of change (-6.433 $\pm 0.493 \mathrm{~g}$ ) of body weight of diabetic treated with T4 was significantly less $(\mathrm{P}<0.001)$ as compared to diabetic control rats (Figure 1$)$.

\section{Behavioral studies}

Thermal and cold hyperalgesia: The tail flick latencies in both hot and cold immersion test of normal and diabetic rats were found to be $13.17 \pm 0.3073,14.33 \pm 0.33336 .500 \pm 0.4282,8.667 \pm 0.2108$ The tail flick latencies in both hot and cold immersion test of diabetic rats were significantly changed $(\mathrm{P}<0.001)$ as compared to normal control. 5 weeks treatment with T4 $9.000 \pm 0.2582,11.50 \pm 0.2236$ significantly $(\mathrm{P}<0.001)$ improved both cold and hot immersion performance (Figures 2 and 3 ).

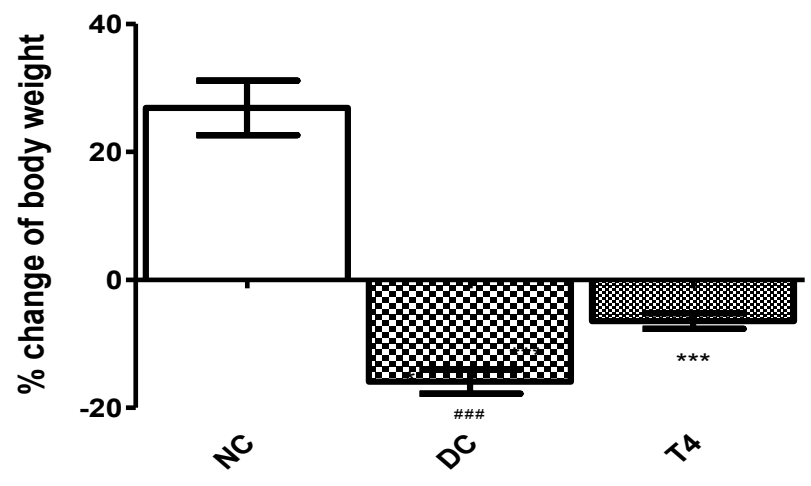

Figure 1: Effect of treatment of thyroxine, for five weeks on \% body weight change in diabetic rats. NC: normal control, DC: diabetic control, T4: thyroxine. Values are represented as mean \pm SEM $(n=6)$. $P<0.001$ Vs normal control group, and ${ }^{* * *} \mathrm{P}<0.001 \mathrm{Vs}$ diabetic control group. One Way ANOVA followed by Bonferroni multiple comparisons.
Measurement of muscle incoordination using Rota rod: Time latencies at $15 \mathrm{rpm}$ of normal and diabetic rats was found to be 103.8 $\pm 1.74,75.5 \pm 1.176$ respectively, and same were significantly reduced $(\mathrm{P}<0.001)$ as compared to normal control. Time latencies of diabetic rats treated with $\mathrm{T} 4$, at $15, \mathrm{rpm}$ was found to be $86.67 \pm 0.8433$ and same was significantly $\mathrm{P}<0.001$ improved (Figure 4 ).

Measurement of grip strength: The grip strength of normal and diabetic rats was found to be $9.822 \pm 0.1332,2.797 \pm 0.1171$ respectively, the grip strength of diabetic rats significantly reduced $(\mathrm{P}<0.001)$ as compared to normal control. The grip strength of diabetic rats treated with T4 was found to be $3.825 \pm 0.1010$ and same was significantly improved $\mathrm{P}<0.001$ as compared to diabetic control (Figure 5).

\section{Biochemical studies}

Estimation of GHb: The percentage of GHb of normal rats was found to be $4.577 \pm 0.0249$, The percentage of $\mathrm{GHb}$ of diabetic rats was found to be $9.537 \pm 0.066$, and same was significantly increased $(\mathrm{P}<0.001)$ as compared to normal control. The percentage of GHb of diabetic rats treated with T4, was found to be $9.357 \pm 0.01838$ and same were significantly improved. $\mathrm{P}<0.05$ when compared $\mathrm{T} 4$ treated diabetic rats with diabetic control (Figure 6).

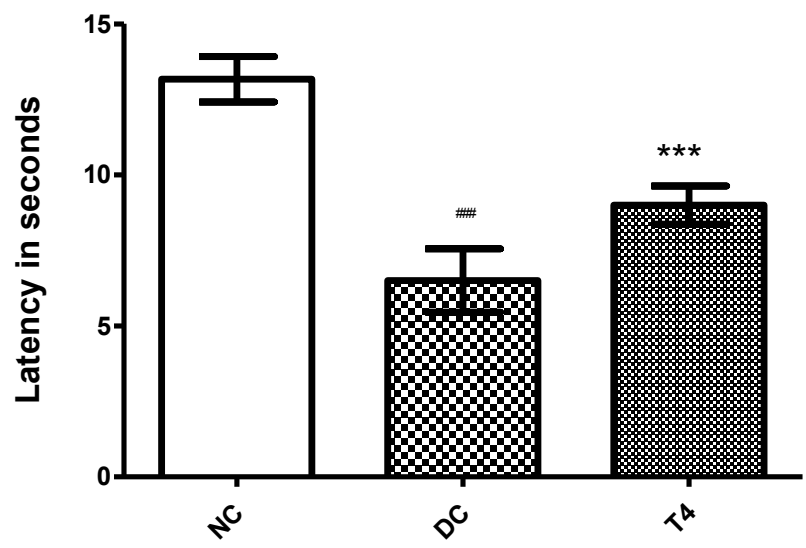

Figure 2: Effect of treatment of thyroxine for five weeks on tail flick latencies $\left(46^{\circ} \mathrm{C}\right)$ in diabetic rats. NC: normal control, DC: diabetic control, T4: thyroxine. Values are represented as mean $\pm \operatorname{SEM}(n=6)$. $P<0.001 \mathrm{Vs}$ normal control group, ${ }^{* * *} P<0.001 \mathrm{Vs}$ diabetic control group. One Way ANOVA followed by Bonferroni multiple comparisons.

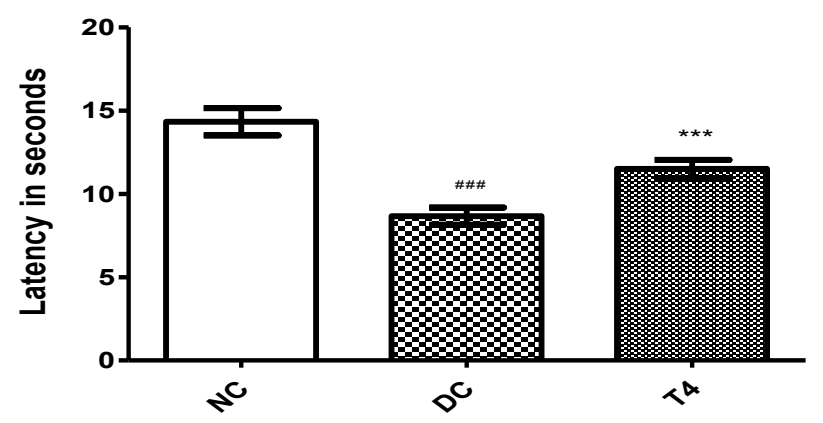

Figure 3: Effect of treatment of thyroxine for five weeks on tail flick latencies $\left(4^{\circ} \mathrm{C}\right)$ in diabetic rats. NC: normal control, DC: diabetic control, T4: thyroxine. Values are represented as mean $\pm \operatorname{SEM}(n=6)$. $P<0.001 \mathrm{Vs}$ normal control group, ${ }^{* * *} \mathrm{P}<0.001 \mathrm{Vs}$ diabetic control group. One Way ANOVA followed by Bonferroni multiple comparisons. 
Citation: Hariprasad MG, Razdan R, Yasha TC, Amrutanand ST (2015) Thyroxine: A Putative Neuroprotectant in Diabetes Induced Peripheral Neuropathy in Rats. J Diabetes Metab 6: 595. doi:10.4172/2155-6156.1000595

Measurement of lipid peroxidation: The sciatic nerve MDA levels of normal rats was found to $1.627 \pm 0.008433$, The sciatic nerve of MDA levels diabetic rats was found to be significantly high $(\mathrm{P}<0.001)$ i.e $3.553 \pm 0.02860$, The sciatic nerve MDA levels of diabetic rats treated with T4 was found to be $3.235 \pm 0.008466$, and same were significantly $(\mathrm{P}<0.001)$ reduced (Figure 7$)$.

Estimation of superoxide dismutase (SOD): Sciatic nerve SOD activity in normal rats was found to be $205.7 \pm 0.1078$, Sciatic nerve SOD activity was significantly $(\mathrm{P}<0.001)$ low $106.8 \pm 0.2798$ in 5 weeks diabetic rats. SOD activity of diabetic rats treated with $\mathrm{T} 4$ was found to be $117.0 \pm 0.1376$. T4 treatment significantly $(\mathrm{P}<0.001)$ restored SOD activity when compared to diabetic control (Figure 8).

Estimation of catalase: Sciatic nerve catalase activity in normal rats was found to be $0.1058 \pm 0.0004$, Sciatic nerve catalase activity was significantly $(\mathrm{P}<0.001)$ low $0.0545 \pm 0.0013$ in 5 weeks diabetic rats. Catalase activity of diabetic rats treated with $\mathrm{T} 4$ was found to be $0.08833 \pm 0.00230$. T4 treatment significantly $(\mathrm{P}<0.001)$ restored catalase activity when compared to diabetic control (Figure 9).

Measurement of reduced glutathione activity: Sciatic nerve glutathione content in normal rats was found to be $78.41 \pm 0.04175$, Sciatic nerve glutathione content was significantly $(\mathrm{P}<0.001)$ low 55.10 \pm 0.05596 in 5 weeks diabetic rats. Glutathione content of diabetic rats treated with $\mathrm{T} 4$ was found to be $61.44 \pm 0.1231$. T4 treatment significantly $(\mathrm{P}<0.001)$ restored glutathione content when compared to diabetic control (Figure 10).

\section{Measurement of Nerve Conduction Velocity (NCV)}

Sciatic NCV was significantly $(\mathrm{P}<0.001)$ reduced in 5 weeks diabetic rats $(44.11 \pm 0.2907)$ when compared to normal $(53.13 \pm 0.4599)$, $\mathrm{T} 4$ treated diabetic rats significantly $(\mathrm{P}<0.05)$ exhibited improved NCV $(45.72 \pm 0.1954)$ (Figure 11).

\section{In-vitro glycation of proteins}

AGEs formation after incubation at $37^{\circ} \mathrm{C}$ for 15 days, with an IC50 value of T4 and the standard amino guanidine was found out to be $410.25 \pm 0.32 \mu \mathrm{g} / \mathrm{ml}$, and $322.4 \pm 2.23 \mu \mathrm{g} / \mathrm{ml}$ respectively. However the concentration of $\mathrm{T} 4$ required for inhibition of glycation of proteins was found to be higher compared to standard amino guanidine (Figure 12).

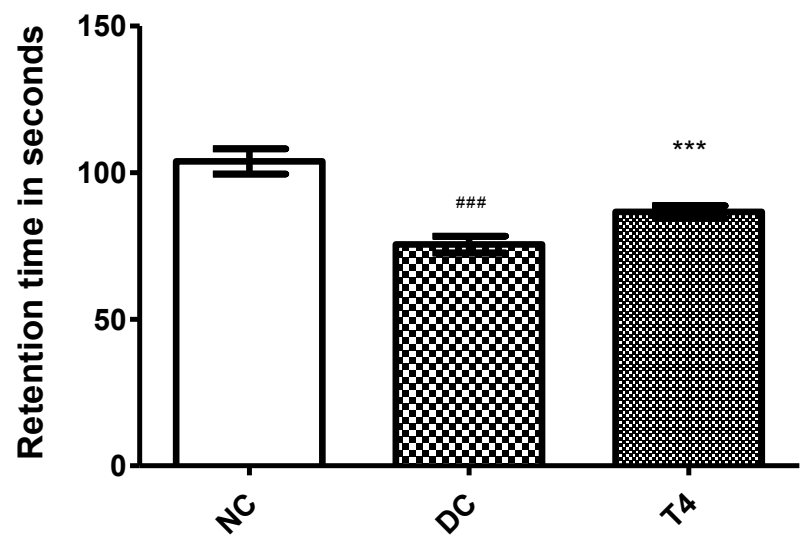

Figure 4: Effect of treatment of thyroxine, for five weeks on muscle incordination by rota rod performance in diabetic rats. NC: normal control, DC: diabetic control, T4: thyroxine .Values are represented as mean \pm SEM $(n=6)$. $\mathrm{N}<0.001 \mathrm{Vs}$. normal control group, ${ }^{* * *} \mathrm{P}<0.001 \mathrm{Vs}$. diabetic control group. One Way ANOVA followed by Bonferroni multiple comparisons.

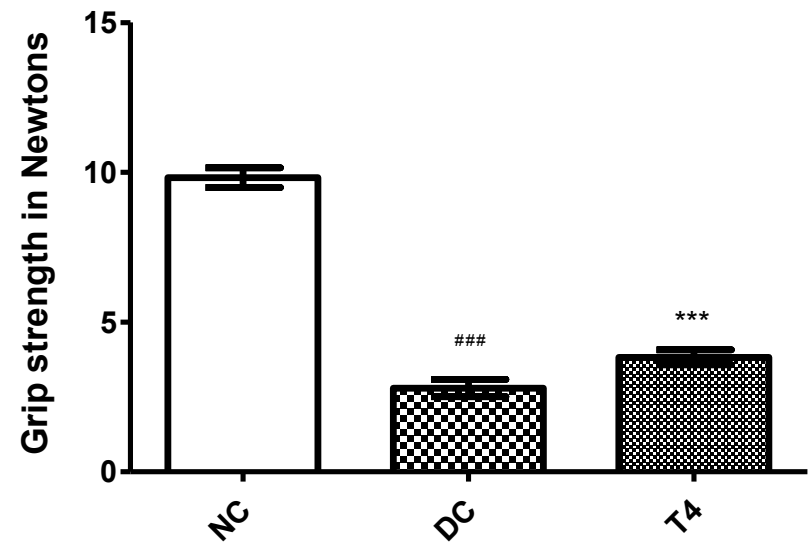

Figure 5: Effect of treatment of thyroxine, erythropoietin, benfotiamine and their combination for five weeks on grip strength in diabetic rats. NC: normal control, DC: diabetic control, T4: thyroxine. Values are represented as mean $\pm \operatorname{SEM}(n=6)$. $P<0.001$ Vs normal control group, ${ }^{* * *} P<0.001$ Vs diabetic control group. One Way ANOVA followed by Bonferroni multiple comparisons.

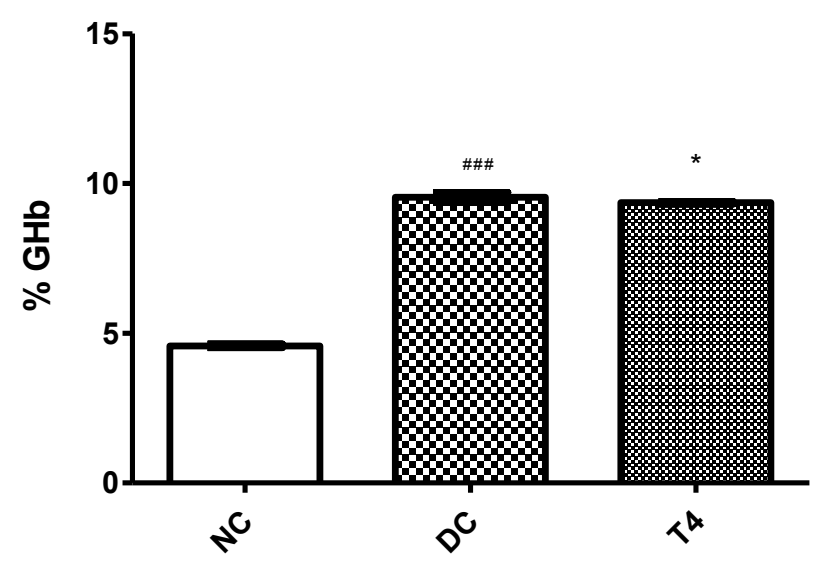

Figure 6: Effect of treatment of thyroxine, for five weeks on $\% \mathrm{GHb}$ in diabetic rats. NC: normal control, DC: diabetic control, T4: thyroxine. Values are represented as mean \pm SEM $(n=6)$. \#\# $P<0.001$ Vs normal control group, ${ }^{*}$ $\mathrm{P}<0.05$, Vs diabetic control group.

\section{Discussion}

Thus the present study demonstrated the protective effect of subcutaneous administration of thyroxine which alleviated the persistence of neuropathic pain (thermal and cold hyperalgesia) in diabetic rats. Administration of thyroxine also improved the delay of sciatic nerve conduction velocity in the diabetic rats. Oxidants and pro oxidants formation are known to be the major cause of diabetic neuropathy, which is diminished after the administration of thyroxine. Our results, therefore, suggest that the subcutaneous administration of thyroxine ameliorated the diabetic neuropathic pain and oxidative stress as a result of which rescue neural functions.

In the current study, we observed a significant increase in the serum glucose level after 48 hours of the STZ administration. This may be due to destruction of pancreatic beta cells, which causes reduction in release of insulin. Along with hyperglycemia symptoms like weight loss, polydipsia, polyuria and polyphagia was also observed which confirmed Type 1 diabetes mellitus in rats. We have observed a 
Citation: Hariprasad MG, Razdan R, Yasha TC, Amrutanand ST (2015) Thyroxine: A Putative Neuroprotectant in Diabetes Induced Peripheral Neuropathy in Rats. J Diabetes Metab 6: 595. doi:10.4172/2155-6156.1000595

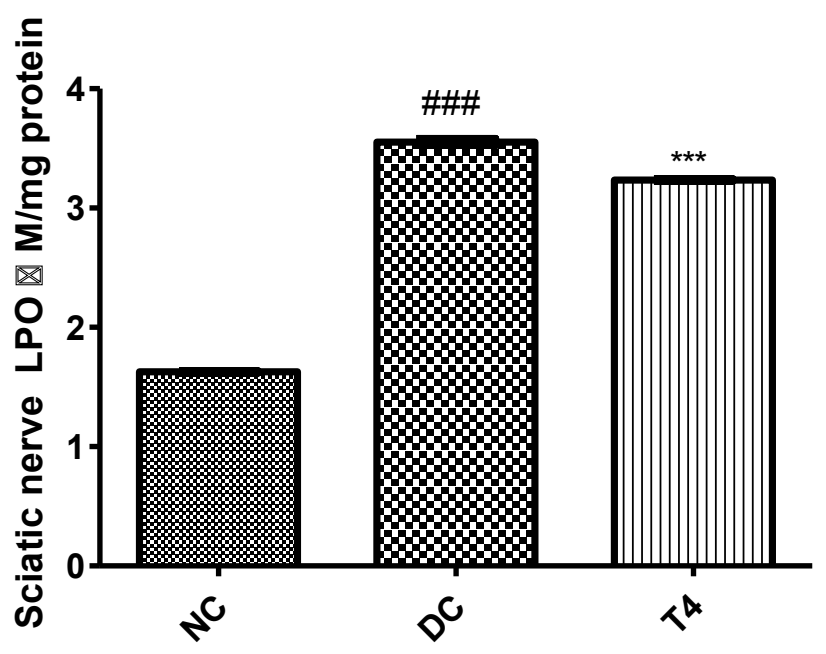

Figure 7: Effect of treatment of thyroxine, for five weeks on $\% \mathrm{GHb}$ in diabetic rats. NC: normal control, DC: diabetic control, T4: thyroxine. Values are represented as mean \pm SEM $(n=6)$. $P<0.001$ Vs normal control group, ${ }^{*}$ $\mathrm{P}<0.05$, Vs diabetic control group.

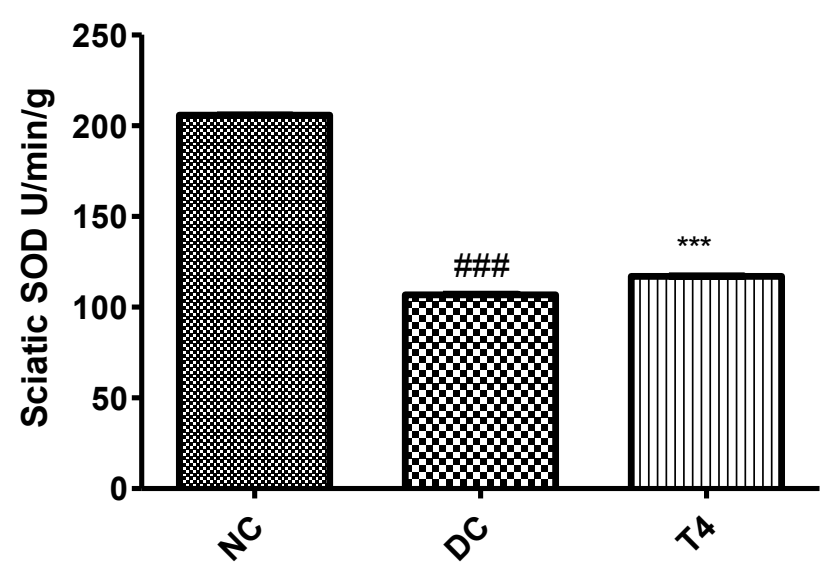

Figure 8: Effect of treatment of thyroxine, benfotiamine and their combination for five weeks on sciatic nerve SOD in diabetic rats. NC: normal control, DC: diabetic control, T4: thyroxine, Values are represented as mean \pm SEM $(n=6)$. $P<0.001$ Vs normal control group, ${ }^{* * *} P<0.001$, Vs diabetic control group. One Way ANOVA followed by Bonferroni multiple comparisons.

significant reduction in the body weight of the diabetic rats as compare to the normal control group. Reduction in the body weight in type 1 diabetes can be due to oxidative degradation of amino acids causing loss of tissue proteins and lipolysis, which leads to muscle wasting. This process causes severe damage the energy reserves in the rats and decreases the body weight as confirmed in our present study. In treated diabetic group the weight loss was significantly prevented by supplementation of thyroxine. Improvement in the weight loss may be due to increase in the rate of metabolism in cell by thyroxine and decrease in the oxidative stress causing preservation of tissue protein by decreasing the muscle wasting contributing to the recovery of body weight.

According to the previous studies rats are frequently focus on their reaction to the nociceptive stimuli, because of the lack of quantifiable signs of spontaneous pain. The nociceptive tests used in the study are

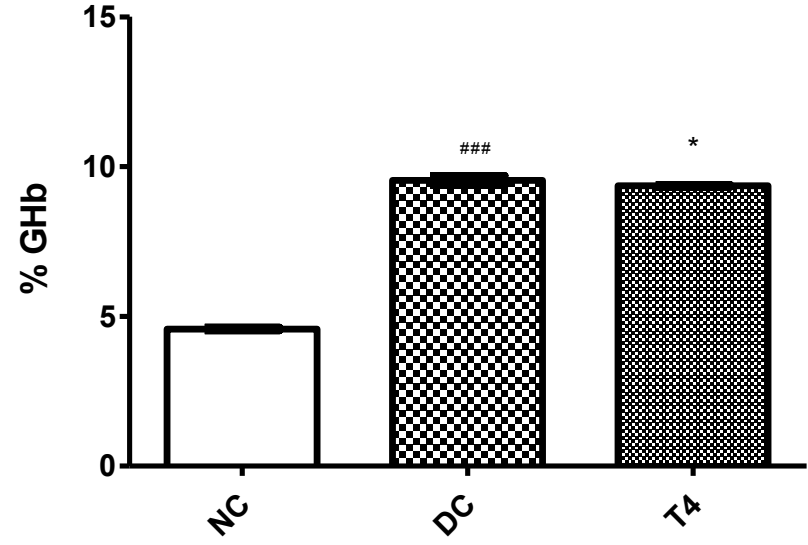

Figure 9: Effect of treatment of thyroxine, benfotiamine and their combination for five weeks on sciatic nerve catalase in diabetic rats. NC: normal control, DC: diabetic control, T4: thyroxine. Values are represented as mean \pm SEM $(n=6)$. $\# \# 0.001$ Vs normal control group, ${ }^{* * *} P<0.001$, Vs diabetic control group. One Way ANOVA followed by Bonferroni multiple comparisons.

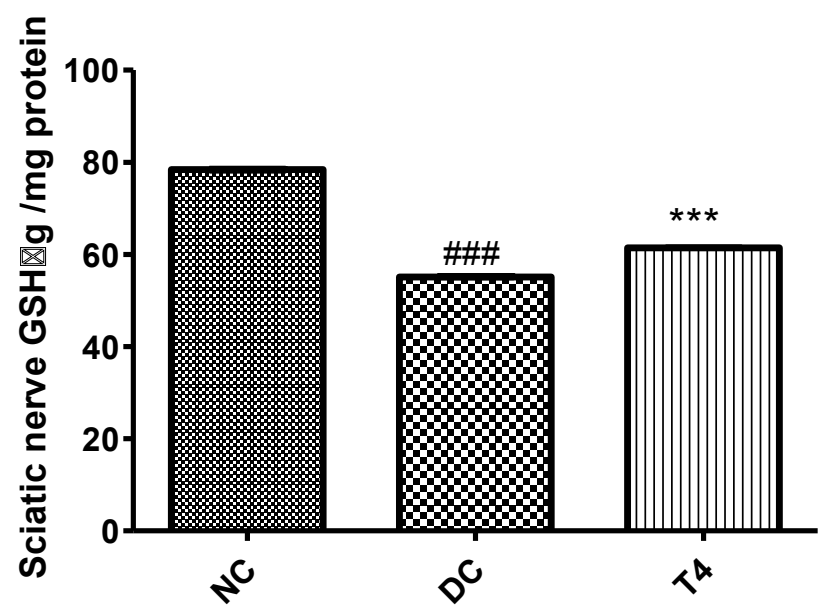

Figure 10: Effect of treatment of thyroxine, benfotiamine and their combination for five weeks on sciatic nerve GSH in diabetic rats. NC: normal control, DC: diabetic control, V T4: thyroxine. Values are represented as mean \pm SEM $(n=6)$. $P<0.001$ Vs normal control group, ${ }^{* * *} P<0.001$, Vs diabetic control group. One Way ANOVA followed by Bonferroni multiple comparisons.

thermal and cold hyperalgisia. These tests are used to measure the latency or withdrawal threshold of the rat whose tail is exposed to thermal and cold stimulation. Primary hyperalgisia is mainly due to sensitization of nociceptive nerve endings. The cold hyperalgesic response in the tail withdrawal test is generally attributed to change in the peripheral and central processing. While the mechanism of thermal hyperalgesia involved sensitization of unmyelinated nociceptors. A marked decrease in nociceptive threshold in STZ induced diabetic rats as compare to normal control rats indicate the development of significant hyperalgesia. As thyroid hormone receptors are highly expressed in brain and have pain sensitivity related to thyroid status. In the present study thyroxine effectively attenuated the hyperalgesia associated with diabetic neuropathy. In STZ induced diabetic neuropathy causing hyperalgesia is often accompanied by motor in coordination and reduced muscle strength. Alteration in diabetes induced motor behavior was previously reported in both human and animal model as a common characteristic 
of many neurological disorders [34]. In the present study diabetic control rats showed a significant reduction in falling latency on rota rod apparatus. The severity of diabetic neuropathy has been associated with decreased muscle strength in both type 1 and type 2 diabetes and weak grip strength in grip strength meter indicating poor motor/muscle activity [35]. Recently researcher have elucidate the influence of glial activation leading to cellular degradation and glutamate toxicity on altered behavioral activity in STZ induced diabetic rats. Glial activation is also responsible for the neuropathic pain and neuroinflammation. In brain thyroxine is activated via conversion of thyroxine to T3 catalyzed by the type 2 iodothyronine deiodinase (D2) in the glial cells present in the astrocytes and tanycytes in the mediobasal hypothalamus. Therefore, the improvement in the muscle coordination and muscular grip strength after thyroxine treatment is may be due to inhibition of glial/microglial activation.

In Type 1 diabetes mellitus an elevation in the glucose level is directly proportional to the rate of glycosylation of hemoglobin causes the formation of $\mathrm{GHb}$ (glycosylated hemoglobin) over previous four weeks to three months. Marked increase in percentage of GHb has been reported in previous studies in diabetic rats [36]. GHb is an average of plasma glucose concentration and has been implicated in various diabetic microvascular complications like neuropathy, nephropathy, retinopathy etc. Previous studies revealed the role of glycosylation leading to the formation of oxygen-derived free radicals in diabetes mellitus and its level can be considered as one of the important marker of oxidative stress. Therefore, in the present study we have measured the level of $\mathrm{GHb}$ as a marker of diabetes induced oxidative stress. Our results showed that the level of GHb in diabetic rats was higher as compare to the normal rats. The treatment with thyroxine significantly reduces the level of $\mathrm{GHb}(\mathrm{p}<0.05)$ in treated diabetic rat could be due to improvement in hyperglycemia. The inhibition activity of T4 on glycation of proteins in-vitro was also measured in our study. T4 inhibited AGE formation in-vitro, however the IC 50 value of T4 was found more compare to standard aminoguanidine

It is evidenced based that diabetic neuropathy is accompanied with the functional changes in the sciatic nerve and can be assessed by nerve conduction velocity (NCV). In our study we found reduction

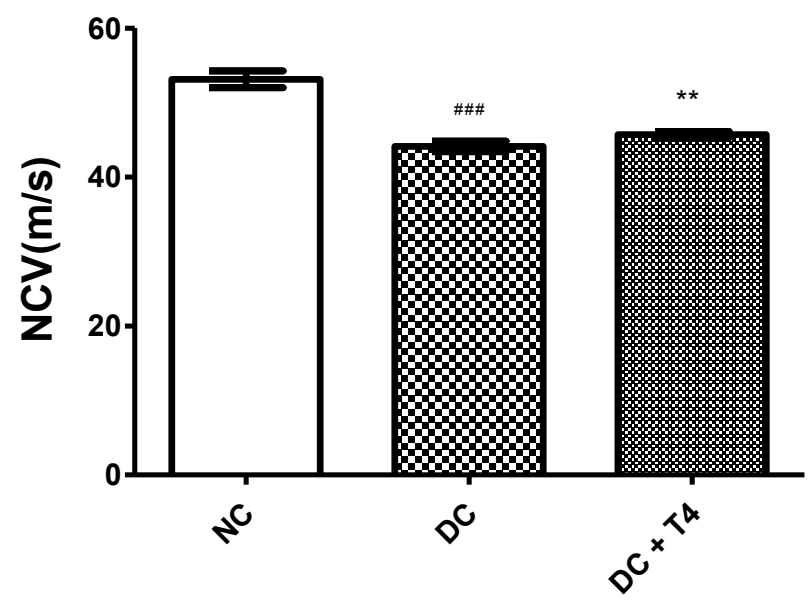

Figure 11: Effect of treatment of thyroxine for five weeks on nerve conduction velocity in diabetic rats. NC: normal control, DC: diabetic control, T4: thyroxine, Values are represented as mean $\pm \operatorname{SEM}(n=6)$. $P<0.001 \mathrm{Vs}$ normal control group, and ${ }^{* *} \mathrm{P}<0.05 \mathrm{Vs}$ diabetic control group. One Way ANOVA followed by Bonferroni multiple comparisons.

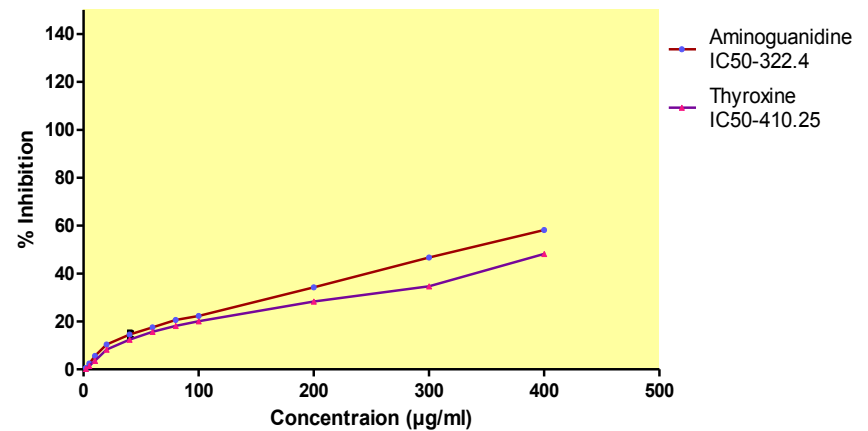

Figure 12: Effect of aminoguanidine and thyroxine, on in-vitro AGE inhibition. AGEs formation after incubation at $37^{\circ} \mathrm{C}$ for 15 days, with an IC50 value of thyroxine and the standard aminoguanidine was found to be $410.25 \pm 0.32 \mu \mathrm{g} /$ $\mathrm{ml}$ and $322.4 \pm 2.23 \mu \mathrm{g} / \mathrm{ml}$ respectively.

in NCV in STZ treated group which confirmed the abnormal functions of nerve due to diabetes. Thyroxine treated group showed a significant improvement in NCV. Hence, subcutaneous administration of thyroxin is leading to normalization of nerve speed at which an electrochemical impulse propagates down a neural pathway. The normalization of NCV can be due to decrease in the oxidative stress. The deficit in nerve conduction velocity was completely prevented by $\mathrm{T} 4$ treatment could be due to increased $\mathrm{Na}+\mathrm{K}+$ ATPase activity, providing neurotrophic support and improving micro vascular circulation [37]. It is well known that diabetes is multiple etiological diseases leading to various pathways causing oxidative stress. Studies have also showed evidence that superoxides and peroxynitrite impairs endothelium dependent vascular relaxation of epineural arterioles of the sciatic nerve in diabetic rats [33]. In addition to vascular mechanisms nonvascular mechanisms like impairment of neurotrophic support have also been reported to cause nerve conduction deficits in DPN [34]. Therefore, the estimation oxidants and anti-oxidants are the important parameter of the study. Prolong hyperglycemia induces carbonyl stress which in turn can lead to lipid peroxidation induced oxidative damage. The increase lipid peroxidation in sciatic nerve homogenate is of may be due to the observed increase in the level of major product of lipid peroxidation i.e. MDA level. In the present study significant MDA levels were observed in the sciatic nerve homogenate of diabetic rat as compare to normal control rats, indicating that the oxidative stress was strengthened during the development of diabetes. Subcutaneous administration of thyroxine alleviated the MDA levels and improved endogenous antioxidants such as GSH, catalase and glutathione in sciatic nerve homogenate.

It is also evidenced that diabetic neuropathy is accompanied with the morphological changes in the sciatic nerve and can be assessed by performing histological studies. Morphological study of siatic nerve of normal rats showed closely packed nerve fibers normal endoneurial matrix separating the nerve fibers, admixture of large and small diameter myelinated fibers (Figure $13 \mathrm{~A}-\mathrm{C}$ ), and the thickness of the myelin sheath is proportionate the width of the axonal diameter (Figure 11E). Conversly, diabetic rats displayed the histological damages including endoneurial vascular thickening (diabetic microangiopathy) (Figure 14C,D) loss of more of small myelinated fibers while large diameter fibers are better preserved (Figure 14 A,B). However, myelin sheath was unaffected by streptozotocin in DPN (Figure 14B). The altered sodium cell gradient due to impairment of $\mathrm{Na}^{+} \mathrm{K}^{+}$ATPase activity leading to altered membrane environment, which in turn causes histological damages, and decrease myelin protein expression. Thyroxine treated 
Citation: Hariprasad MG, Razdan R, Yasha TC, Amrutanand ST (2015) Thyroxine: A Putative Neuroprotectant in Diabetes Induced Peripheral Neuropathy in Rats. J Diabetes Metab 6: 595. doi:10.4172/2155-6156.1000595
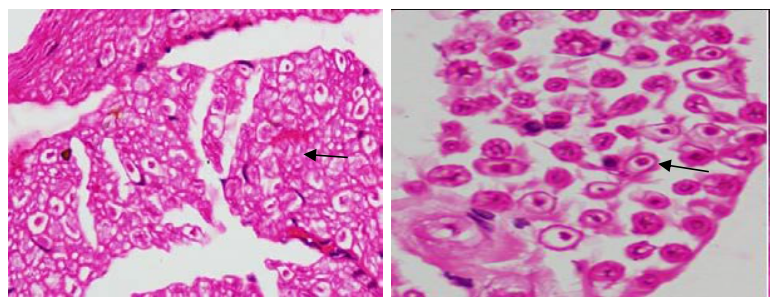

A. Hematoxlyin and Eosin 160X B.Hematoxlyin and Eosin 160X

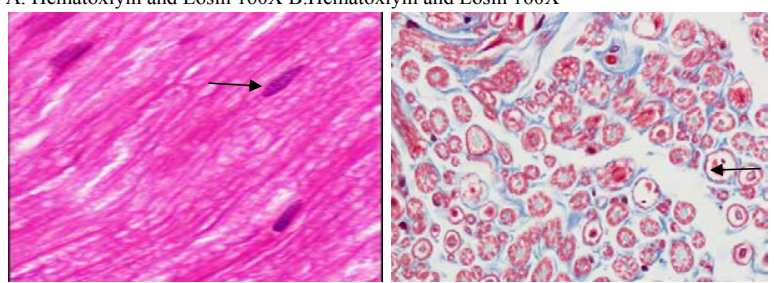

C.Hematoxlyin and Eosin 160X D.Masson's trichrome $160 \mathrm{X}$

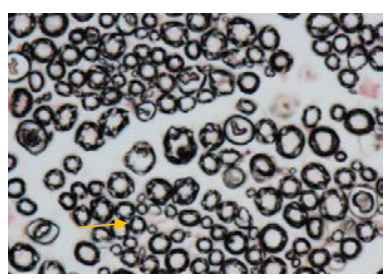

E. Kulchitsky pal stain $160 \mathrm{X}$

Figure 13: Histology of rat sciatic nerve of normal control group: (A) light microscopy transverse section showing closely packed nerve fibers and an occasional endoneurial blood vessel. (B) light microscopy transverse section showing individual nerve fibers and a central axon surrounded by a sheath of myelin.(C) longitudinal section showing the elongated schwann cell nuclei and longitudinally oriented axons with myelin sheaths.(D) transverse section of special stain for collagen highlights the endoneurial matrix separating the nerve fibers and collagenous component is stained blue. $(E)$ transverse section of special stain for myelin reveals an admixture of large and small diameter myelinated fibers. The thickness of the myelin sheath is proportionate the width of the axonal diameter.
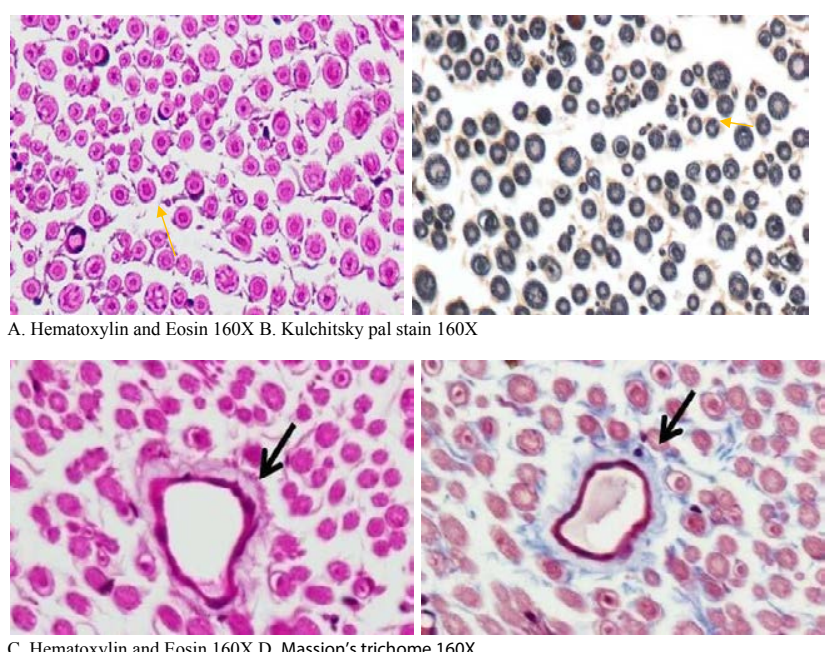

Figure 14: Histology of rat sciatic nerve of STZ (Diabetes) control group. (A) light microscopy of transverse section showing reduced nerve fiber density in the endoneurium.(B) transverse section of special stain for myelin reveals more of small myelinated fibers affected while large diameter fibers are better preserved, myelin sheaths are of normal thickness.(C) transverse section show diabetic microangipathic changes with endoneurial vessel wall thickening and collagenous hyalinization highlighted by the masson's trichrome stain (D).

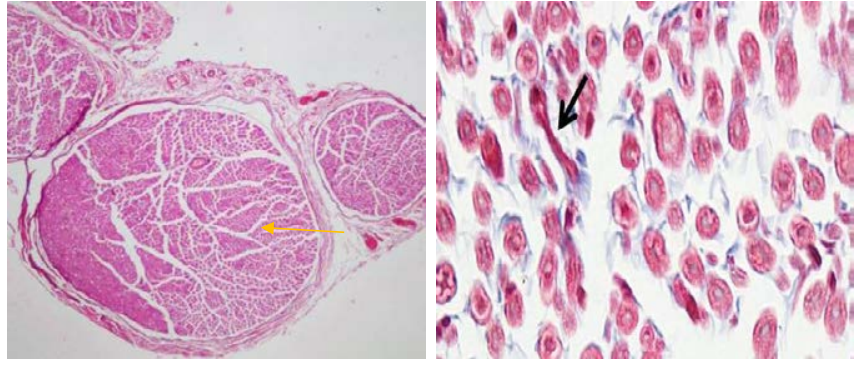

A. Hematoxylin and Eosin 40X B.Massion's trichome 160X

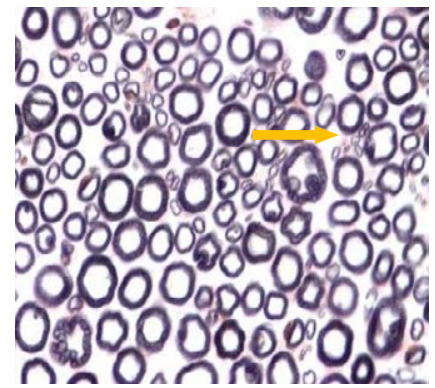

C. Kulchitsky pal stain $160 \mathrm{X}$

Figure 15: Histology of rat sciatic nerve of STZ (Diabetes) control treated with thyroxine. (A) light microscopy of transverse section showing preserved fiber density. (B) transverse section showing absence of diabetic vascular changes no vascular thickening to mild vascular thickening (arrow).(C) transverse section of special stain for myelin show near normal density of fibers with preservation of small and large diameter fibers, presence of regenerating nerve clusters.

rats sections showed absence of diabetic vascular changes no vascular thickening to mild vascular thickening (Figure 15B) normal density of fibers with preservation of small and large diameter fibers, presence of regenerating nerve clusters (Figure 15C). Thus treatment with thyroxine for five weeks almost completely prevented the histological damages induced by diabetes. Thyroxine could probably prevent the histological damages induced by diabetes due to prevention of hyperglycemia induced vascular and non-vascular mechanisms.

Uncontrolled hyperglycemia causes glycation process which causes non enzymatic glycation of various types of protein and chemical modification, resulting in the generation of irreversible heterogenous by products termed as advance glycation end product (AGEs). The accumulation plays a primary role in diabetic complication. Free radicals are also known to stimulate advanced glycation end production by autoxidation of sugars. Therefore in-vitro AGE inhibitory activity was performed to determine the tendency of thyroxine to inhibit AGE formation when compared with standard aminoguanidine. Thyroxine showed higher IC50 value $(410.25 \pm 0.32 \mu \mathrm{g} / \mathrm{ml})$ as compare to standard aminoguanidine $(322.4 \pm 2.23 \mu \mathrm{g} / \mathrm{ml})$. Therefore in-vitro AGE inhibitory activity of thyroxine would be also contributing factor in preventing DPN, however the thyroxine showed higher IC50 value.

\section{Conclusion}

Thyroxine treatment effectively prevented many of behavioral, biochemical, electrophysiological and histological manifestations of STZ induced DPN by decreasing thermal, cold hyperalgesia, improving motor coordination, grip strength, endogenous antioxidants, NCV, fiber density. Decreasing endoneurial vascular thickening, However thyroxine was able to inhibit in-vitro AGE formation at higher dose. 
Citation: Hariprasad MG, Razdan R, Yasha TC, Amrutanand ST (2015) Thyroxine: A Putative Neuroprotectant in Diabetes Induced Peripheral Neuropathy in Rats. J Diabetes Metab 6: 595. doi:10.4172/2155-6156.1000595

\section{References}

1. Sivakumar S, Subramanian SP (2009) Pancreatic tissue protective nature of D-Pinitol studied in streptozotocin-mediated oxidative stress in experimental diabetic rats. Eur J Pharmacol 622: 65-70.

2. Hyllienmark L, Jonsson B, Ekberg K, Lindström P (2009) Abnorma cold perception in the lower limbs: a sensitive indicator for detection of polyneuropathy in patients with type 1 diabetes mellitus. Diabetes Res Clin Pract 85: 298-303.

3. Vincent AM, Russell JW, Low P, Feldman EL (2004) Oxidative stress in the pathogenesis of diabetic neuropathy. Endocr Rev 25: 612-628.

4. Head RJ, McLennan PL, Raederstorff D, Muggli R, Burnard SL, et al. (2000) Prevention of nerve conduction deficit in diabetic rats by polyunsaturated fatty acids. Am J Clin Nutr 71: 386S-92S

5. Estrella JS, Nelson RN, Sturges BK, Vernau KM, Williams DC, et al. (2008) Endoneurial microvascular pathology in feline diabetic neuropathy. Microvasc Res 75: 403-410.

6. Soignet SL, Maslak P, Wang ZG, Jhanwar S, Calleja E, et al. (1998) Complete remission after treatment of acute promyelocytic leukemia with arsenic trioxide. N Engl J Med 339: 1341-1348.

7. Scheindlin S (2006) Rare diseases, orphan drugs, and orphaned patients. Mo Interv 6: 186-191.

8. Ashburn TT, Thor KB (2004) Drug repositioning: identifying and developing new uses for existing drugs. Nat Rev Drug Discov 3: 673-683.

9. Dimasi JA (2001) New drug development in the United States from 1963 to 1999. Clin Pharmacol Ther 69: 286-296.

10. DiMasi JA, Hansen RW, Grabowski HG (2003) The price of innovation: new estimates of drug development costs. J Health Econ 22: 151-185.

11. Goodman \& Gill man's (2001) The Pharmacological basis of therapeutics: 10th ed. New York: Mac Graw-Hill Medical Publishing Division.

12. Tortora GJ (2003) Principles of Anatomy and Physiology: 10th ed. New Jersy: Grabowski SR John Wiley \& Sons Inc.

13. Ledda-Columbano GM, Perra A, Pibiri M, Molotzu F, Columbano A (2005) Induction of pancreatic acinar cell proliferation by thyroid hormone. J Endocrinol 185: 393-399.

14. Verga FC, Panacchia L, Bucci B, Stigliano A, Caballo MG, et al. (2006) 3,5,3'-Triiodothyronine (T3) is a survival factor for pancreatic $\beta$-cells undergoing apoptosis. Journal of Cellular Physiology 206: 309-321.

15. Bakker SJ, ter Maaten JC, Popp-Snijders C, Heine RJ, Gans RO (1999) Triiodothyronine: a link between the insulin resistance syndrome and blood pressure? J Hypertens 17: 1725-1730.

16. Misiti S, Anastasi E, Sciacchitano S, Verga Falzacappa C, Panacchia L, et al. (2005) 3,5,3'-Triiodo-L-thyronine enhances the differentiation of a human pancreatic duct cell line (hPANC-1) towards a beta-cell-Like phenotype. J Cell Physiol 204: 286-296.

17. Cortizo AM, Chazenbalk GD, de Gagliardino EE, García ME, Pisarev MA et al. (1987) Thyroid hormone binding and deiodination by pancreatic islets: relationship with the in vitro effect upon insulin secretion. Acta Endocrinol (Copenh) 116: 66-72.

18. Jansen MS, Cook GA, Song S, Park EA(2000) Thyroid hormone regulates carnitine palmitoyl transferase I alpha gene expression through elements in the promoter and first intron. Journal of Biological Chemistry 275: 34989-34997.

19. Saini AK, Kumar H S A, Sharma SS (2007) Preventive and curative effect of edaravone on nerve functions and oxidative stress in experimental diabetic neuropathy. Eur J Pharmacol 568: 164-172.
20. Calza L, Fernandez M, Giuliani A, Aloe L, Giardino L (2002) Thyroid hormone activates oligodendrocyte precursors and increases a myelin-forming protein and NGF content in the spinal cord during experimental allergic encephalomyelitis. Proceedings of the National Academy of Sciences 99: 3258-3263.

21. Federiuk IF, Casey HM, Quinn MJ, Wood MD, Ward WK (2004) Induction of type-1 diabetes mellitus in laboratory rats by use of alloxan: route of administration, pitfalls, and insulin treatment. Comp Med 54: 252-257.

22. Ling B, Authier N, Balayssac D, Eschalier A, Coudore F (2007) Behavioral and pharmacological description of oxaliplatin-induced painful neuropathy in rat. Pain 128: 225-234.

23. Peeyush KT, Gireesh G, Jobin M, Paulose CS (2009) Neuroprotective role of curcumin in the cerebellum of streptozotocin-induced diabetic rats. Life Sci 85: 704-710.

24. Ali A, Ahmad FJ, Pillai KK, Vohora D (2004) Evidence of the antiepileptic potential of amiloride with neuropharmacological benefits in rodent models of epilepsy and behavior. Epilepsy Behav 5: 322-328.

25. Nathan DM, Singer DE, Hurxthal K, Goodson JD (1984) The clinical information value of the glycosylated hemoglobin assay. N Engl J Med 310: 341-346.

26. Eliasson SG (1964) Nerve Conduction Changes in Experimental Diabetes. Clin Invest 43: 2353-2358.

27. Tiwari V1, Kuhad A, Chopra K (2009) Tocotrienol ameliorates behavioral and biochemical alterations in the rat model of alcoholic neuropathy. Pain 145: 129135

28. Jiang Y, Guo C, Vasko MR, Kelley MR (2008) Implications of apurinic/ apyrimidinic endonuclease in reactive oxygen signaling response after cisplatin treatment of dorsal root ganglion neurons. Cancer Res 68: 6425-6434.

29. Jung $\mathrm{CH}$, Seog HM, Choi IW, Choi HD, Cho HY (2005) Effects of wild ginseng (Panax ginseng C.A. Meyer) leaves on lipid peroxidation levels and antioxidant enzyme activities in streptozotocin diabetic rats. J Ethnopharmacol 98: 245250.

30. Aebi H (1984) Catalase in vitro. Methods Enzymol 105: 121-126.

31. van Doorn R, Leijdekkers CM, Henderson PT (1978) Synergistic effects of phorone on the hepatotoxicity of bromobenzene and paracetamol in mice. Toxicology 11: 225-233.

32. Rosa Martha Perez Gutierrez (2012).Inhibition of Advanced Glycation End Product Formation by Origanum majorana L. In Vitro and in StreptozotocinInduced Diabetic Rats. Evidence-Based Complementary and Alternative Medicine.

33. Wuarin-Bierman L, Zahnd GR, Kaufmann F, Burcklen L, Adler J (1987) Hyperalgesia in spontaneous and experimental animal models of diabetic neuropathy. Diabetologia 30: 653-658.

34. Cendelín J, Korelusová I, Vozeh F (2008) The effect of repeated rotarod training on motor skills and spatial learning ability in Lurcher mutant mice. Behav Brain Res 189: 65-74.

35. Andersen $\mathrm{H}$, Nielsen S, Mogensen CE, Jakobsen J (2004) Muscle strength in type 2 diabetes. Diabetes 53: 1543-1548.

36. Krishnamurti U, Steffes MW (2001) Glycohemoglobin: a primary predictor of the development or reversal of complications of diabetes mellitus. Clin Chem 47: $1157-1165$

37. Fernandez M, Giuliani A, Pirondi S, Intino Giulia, Giardino L, Aloe L (2004). Thyroid hormone administration enhances remyelination in chronic demyelinating inflammatory disease. PNAS 101: 16363-16368 